\title{
PENGARUH SELF-ESTEEM DAN KOMUNIKASI INTERPERSONAL TERHADAP EFEKTIVITAS KERJA GURU
}

\author{
Theresia Sulastri $^{a)}$, Sumardi $^{\left.b^{*}\right)}$, Yossa Istiadi $^{b)}$ \\ a) SMP Gunug Putri, Bogor, Indonesia \\ a) Universitas Pakuan, Bogor, Indonesia \\ ${ }^{*}$ e-mail korespondensi: sumardi@unpak.ac.id
}

riwayat artikel : diterima: 06 November 2019; direvisi: 16 Desember 2019; disetujui: 06 Januari 2020

\begin{abstract}
Abstrak. Efektivitas kerja guru sangat menentukan keberhasilan pencapaian tujuan sekolah. Studi awal di beberapa kalangan SMP Swasta di wilayah Kecamatan Gunung Putri menunjukan bahwa pencapaian tersebut belum signifikan sehingga berpotensi menjadi kendala dalam pencapaian tujuan sekolah. Perlu diupayakan peningkatan efektivitas kerja guru melalui penguatan faktor-faktor yang mempengaruhinya, diantaranya self-esteem dan komunikasi interpersonal. Penelitian ini bertujuan untuk mendeskripsikan, menganalisis serta mengetahui pengaruh self-esteem dan komunikasi interpersonal terhadap efektivitas kerja guru. Penelitian ini menggunakan metode survei kuantitatif dengan dengan pendekatan analisis jalur. Penelitian ini dilakukan pada guru-guru SMP Swasta yang berada di Wilayah Kecamatan Gunung Putri Kabupaten Bogor yang berasal dari 5 sekolah. Sampel diambil secara random proporsional yang berjumlah 109 dari 150 populasi. Pengumpulan data menggunakan kuisioner sebagai instrumen. Hasil penelitian menunjukkan bahwa: 1) Terdapat pengaruh positif dan sangat signifikan self-esteem terhadap efektivitas kerja guru dengan koefisien korelasi $\left(\beta_{\mathrm{y} 1}\right)$ sebesar 0,4769 dan persamaan regresi $\hat{Y}=65,08+0,53$ X1, koefisien determinasi 0,2275 , artinya sebesar $22,75 \%$ pengaruh langsung self-esteem guru yang menyebabkan meningkatnya efektivitas kerja guru, 2) Terdapat pengaruh positif dan sangat signifikan komunikasi personal terhadap efektivitas kerja guru dengan koefisien korelasi $\left(\beta_{\mathrm{y} 2}\right)$ sebesar 0,5051 dan persamaan regresi $\hat{Y}=59,52+0,55 X 2$, koefisien determinasi sebesar 0,2552 artinya $25,52 \%$ pengaruh langsung komunikasi personal guru yang menyebabkan peningkatan efektivitas kerja guru makin tinggi, 3) Terdapat pengaruh positif dan sangat signifikan selfesteem dan komunikasi personal terhadap efektivitas kerja guru dengan koefisien korelasi $\left(\beta_{\mathrm{y} 12}\right)$ sebesar 0,5704 dan persamaan regresi $\hat{\mathrm{Y}}=35,21+0,35 \mathrm{X} 1+0,40 \mathrm{X} 2$, dan secara bersama-sama self-esteem dan komunikasi personal guru mempengaruhi meningkatnya efektivitas kerja guru sebesar 69,81\%. Dapat disimpulkan bahwa peningkatan efektivitas kerja guru dipengaruhi oleh peningkatan self-esteem dan komunikasi interpersonal.
\end{abstract}

Kata Kunci: Self-esteem, komunikasi interpersonal, dan efektivitas kerja

\section{EFFECT OF SELF-ESTEEM AND INTERPERSONAL COMMUNICATION TOWARD TEACHER EFFECTIVENESS}

\begin{abstract}
Teacher's work effectiveness is the one of the elements to be performed in order to reach the school goal. According to the initial study, it is showed that the effectiveness of some private junior high school teachers were not as expected, while actually high work effectiveness among teachers might support excellent output quality implementation. This study aimed to describe, analyze and find out that self-esteem and interpersonal communication bring a positive influence on teacher work effectiveness. The research method was quantitative research and survey research method was path analysis approach. This research was conducted on 5 private junior high schools in the District of Gunung Putri, Bogor Regency. Samples were taken randomly proportionally, totaling 109 of the 150 population. Data collection in this study was using questionnaires as instruments. The results showed that: 1) There was a positive and very significant effect of self-esteem on teacher work effectiveness with a correlation coefficient $(\beta$ y1) of $0.4769 ; 2)$ There was a positive and very significant effect of personal communication on teacher work effectiveness with a correlation coefficient ( $\beta$ y2) of $0.5051 ; 3)$ There was a positive and very significant influence on self-esteem and personal communication on work effectiveness teacher with a correlation coefficient ( $\beta$ y12) of 0.5704 . Based on the results of the study, the teacher's work effectiveness increased as the influence of self-esteem and interpersonal communication.
\end{abstract}

Keywords: Self-Esteem, Interpersonal Communication and Work Effectiveness.

\section{PENDAHULUAN}

Perubahan lingkungan, teknologi dan sistem pendidikan harus didukung oleh kemampuan adaptasi dari seluruh praktisi pendidikan termasuk guru. Guru menjadi bagian penting dan merupakan kunci utama dalam pencapaian tujuan sekolah. Oleh karena itu kompetensi profesional guru perlu terus ditingkatkan dan dikembangkan dengan berbagai cara, antara lain melalui pendidikan, pelatihan dan pembinaan teknis yang dilakukan secara berkesinambungan di sekolah. Guru merupakan elemen terpenting dalam meningkatkan kualitas pendidikan, oleh sebab itu perhatian terhadap kerja guru menjadi penting juga.

Sebagai seorang profesional, guru memiliki tugas utama mendidik, mengajar, melatih, serta mengarahkan peserta didik agar memiliki bekal sikap dan keterampilan dalam menghadapi persaingan global. Oleh karena itu tugas guru sebagai tenaga 
profesional yang mampu bekerja secara efektif menjadi sangat penting untuk terwujudnya tujuan penyelenggaran pembelajaran di sekolah.

Gibson et al., (2009:21-25), menjelaskan pemahaman efektivitas dari aspek goal approach (pendekatan tujuan), yaitu pencapaian tujuan yang diakui dari usaha kerjasama, dimana tingkat pencapaian tujuan menunjukkan tingkat efektivitas. Pendekatan tujuan merefleksikan rasionalitas, kegunaan, arah tujuan, dan pencapaian. Selanjutnya Gibson et al., (2012: 78-80) menjelaskan efektivitas kerja adalah hasil kerja yang terkait dengan tujuan organisasi seperti kualitas, efisiensi dan kriteria keefektifan lain yang dicapai selama periode tertentu melalui usaha yang membutuhkan kemampuan dan keterampilan serta pengalaman. Menurut Danim (2004:50) istilah efektivitas kerja dapat dibagi dalam dua hal. Pertama, efektivitas kerja dalam konteks individu yaitu seseorang dalam melakukan sesuatu yang tepat sesuai dengan tujuan atau sasaran yang ditetapkan dalam organisasi didasarkan pada keahlian terampil yang dimiliki. Kedua dalam koteks organisasi istilah efektivitas kerja digunakan untuk mengukur keberhasilan sebuah organisasi yang terkait dengan program-program dan memberikan kegunaan bagi organisasi. Kerja guru itu bisa ditingkatkan dengan beberapa cara diantaranya adalah lembaga organisasi yang dapat membuat iklim organisasi yang berpihak pada guru (Suchyadi, 2019). Berkaitan dengan lembaga sekolah, Supardi (2013:164) menyatakan bahwa efektivitas adalah terlaksananya kegiatan dengan baik, teratur, bersih, rapi, dan sesuai. Sejalan dengan pengertian tersebut, Robbins dan Judge (2007:27) menyatakan effectiveness is achievement of goals, ini berarti bahwa efektivitas merupakan ketercapaian dari tujuan-tujuan yang telah direncanakan ngan ketentuan.

Nelson dan Quick (2006: 191-193) menjelaskan bahwa kinerja merupakan ketercapaian tujuan kerja. Kerja dalam sebuah organisasi sangat beragam, oleh karena itu ukuran-ukuran dari ketercapaian kerja perlu ditetapkan oleh setiap bagian kerja. Dimensi kinerja yaitu: (1) hasil kerja yang terukur dan kuantitatif, (2) hasil kerja yang kualitatif atau kurang bisa diukur. Penilaian efektivitas kerja menurut Cascio (2004:55) adalah gambaran mengenai kekuatan dan kelemahan individu atau kelompok. Penilaian efektivitas kerja digunakan oleh organisasi untuk menggambarkan bagaimana suatu proses seharusnya bekerja dan bagaimana pekerjaan tersebut seharusnya dilakukan. Riggio (2012:75) juga menyatakan bahwa pada dasarnya penilaian efektivitas kerja adalah menilai dan mengukur kerja individu atau kelompok sesuai dengan batas standar yang telah ditentukan oleh organisasi. Dari beberapa konsep yang telah di jelaskan di atas dapat disintesiskan bahwa efektivitas kerja guru adalah tindakan yang dilakukan oleh seorang guru yang bertujuan untuk mencapai pembelajaran yang terorganisir dan berkualitas sesuai dengan waktu yang telah ditetapkan dengan memanfaatkan segala sumber daya secara akurat.

Rumusan self-esteem dinyatakan Rahman (2013:91) sebagai sesuatu yang sifatnya alamiah dari dalam diri individu yang berpengaruh pada proses berfikir, emosi, keinginan, nilai-nilai, dan tujuan individu. Sejalan dengan pendapat ini, Luxmoore (2008:88) menyatakan bahwa fitrah dari self-esteem adalah secara lahiriah diberikan oleh Tuhan yang menciptakan manusia dan setiap manusia dibekali kepercayaan bahwa dirinya adalah segalanya Pentingnya penguatan self-esteem dijelaskan Sorensen (2006:151), bahwa semakin baik kemajuan seseorang dalam mengatasi perasaan harga diri yang rendah maka akan semakin sedikit kekeliruan dalam kerusakan yang dibuat dan individu akan lebih baik dalam mengontrol emosinya. Hal ini juga disampaikan Schiraldi (2007:100) yang menyatakan bahwa pentingnya individu untuk meningkatkan self-esteem mereka karena terkait dengan kebahagiaan, ketahanan psikologis dan motivasi untuk hidup produktif dan sehat. Dari beberapa kajian teori yang telah dijelaskan di atas dapat disintesiskan bahwa self-esteem adalah sebuah keadaan dimana seorang guru melakukan sebuah evaluasi dan penilaian diri yang berbentuk penilaian menyenangkan atau tidak menyenangkan atas diri sendiri.

DeVito (2002:68) menyampaikan pengertian komunikasi interpersonal sebagai pertalian verbal dan nonverbal antara dua (atau kadangkala lebih dari dua) orang yang saling tergantung satu dengan yang lainnya. Indikator-indikatornya adalah keterbukaan, empati, perilaku mendukung, perilaku positif dan kesetaraan. Sedangkan Pearson (2010:49) menjelaskan bahwa komunikasi interpersonal adalah proses yang menggunakan pesan-pesan untuk menggapai kesamaan makna antara-paling tidakantara dua orang didalam sebuah suasana yang amat mungkin adanya kesempatan yang mirip bagi pembicara dan pendengar. Pengertian komunikasi interpersonal dijelaskan Adler (2009:66) sebagai semua komunikasi antara dua orang atau secara kontekstual komunikasi interpersonal. Menurut Luthans (2011:121), dalam komunikasi interpersonal, penekanan utamanya adalah pada transfer informasi dari satu orang ke orang lain. Komunikasi dipandang sebagai metode dasar perubahan perilaku, dan itu menggabungkan proses psikologis (persepsi, pembelajaran, dan motivasi) di satu sisi dan bahasa di sisi lain. Pada dasarnya, komunikasi terkait dengan tindakan, oleh satu orang atau lebih yang mengirim dan menerima pesan, terjadi dalam suatu konteks tertentu, mempunyai pengaruh tertentu, dan ada kesempatan untuk melakukan umpan balik. Pengertian komunikasi interpersonal menurut Gibson (2012:449-455) adalah komunikasi yang mengalir dari individu ke individu dalam tatap muka dan pengaturan grup. Agar komunikasi interpersonal efektif, perlu memperhatikan hal-hal berikut: (1) menindaklanjuti agar tidak terjadi asumsi yang keliru, (2) mengatur arus informasi agar optimal, (3) Menggunakan umpan balik, (4) mengembangkan empati, (5) menggunakan pengulangan pesan, (6) mendorong rasa saling percaya, (7) menyampaikan pada waktu yang efektif, (8) menyederhanakan bahasa, dan (9) menjadi pendengar efektif.

Berdasarkan beberapa konsep di atas, dapat disintesiskan bahwa komunikasi interpersonal adalah keadaan dimana terjadinya pergantian pesan antara komunikan dan komunikator akibat dari adanya penyampaian pesan, informasi, pikiran dan sikap tertentu dari keduanya. Tujuan dari komunikasi dari komunikasi interpersonal tersebut untuk keterbukaan pengertian dan identifikasi masalah yang akan berujung pada perubahan perilaku dari seorang individu. 


\section{METODE PENELITIAN}

Penelitian ini adalah penelitian kuantitatif menggunakan metode survei. Populasi penelitian adalah guru-guru di 6 (enam) Sekolah Menengah Pertama swasta di wilayah Kecamatan Gunung Putri, Kabupaten Bogor, berjumlah 150 orang. Sampel penelitian adalah 109 guru. Analisis data menggunakan analisis jalur (Path analysis).

\section{HASIL DAN PEMBAHASAN}

\section{Pengujian Hipotesis}

\section{Matriks korelasi}

Mengacu pada analisis korelasi bivariate Pearson dengan program SPSS yang bertujuan untuk menguji adakah pengaruh yang signifikan antara self-esteem dan komunikasi interpersonal terhadap efektivitas kerja guru, sebagaimana tersaji pada Tabel 1..

Tabel 1. Analisis korelasi bivariate pearson pengaruh self-esteem dan komunikasi interpersonal terhadap efektivitas kerja

\begin{tabular}{|c|c|c|c|c|}
\hline & & $\mathrm{Y}$ & $\mathrm{X}_{1}$ & $\mathrm{X}_{2}$ \\
\hline \multirow[t]{3}{*}{$\mathrm{Y}$} & Pearson Correlation & 1 & $.477^{* *}$ & $.505^{* *}$ \\
\hline & Sig. (2-tailed) & &, 000 &, 000 \\
\hline & $\mathrm{N}$ & 109 & 109 & 109 \\
\hline \multirow[t]{3}{*}{$\mathrm{X} 1$} & Pearson Correlation & $.477^{* *}$ & 1 & $.447^{* *}$ \\
\hline & Sig. (2-tailed) &, 000 & & ,000 \\
\hline & $\mathrm{N}$ & 109 & 109 & 109 \\
\hline \multirow[t]{3}{*}{$\mathrm{X} 2$} & Pearson Correlation & $.505^{* *}$ & $.447^{* *}$ & 1 \\
\hline & Sig. (2-tailed) &, 000 &, 000 & \\
\hline & $\mathrm{N}$ & 109 & 109 & 109 \\
\hline
\end{tabular}

Mengacu pada tabel di atas, dapat dinyatakan simpulan sebagai berikut:

a. Berdasarkan nilai signifikan Sig. (2-tailed), dari tabel out put di atas nilai Sig. (2-tailed) antara variabel self-esteem $\left(\mathrm{X}_{1}\right)$ dengan variabel efektivitas kerja $(\mathrm{Y})$ adalah sebesar $0,000<0,05$, yang berarti terdapat korelasi yang signifikan antara variabel self-esteem $\left(\mathrm{X}_{1}\right)$ dengan variabel efektivitas kerja $(\mathrm{Y})$. Hubungan antara variabel komunikasi interpersonal $\left(\mathrm{X}_{2}\right)$ dengan variabel efektivitas kerja (Y) memiliki nilai Sig. (2-tailed) sebesar 0,000 $<0,05$, yang berarti terdapat korelasi yang signifikan antara variabel komunikasi interpersonal $\left(\mathrm{X}_{2}\right)$ dengan variabel efektivitas kerja $(\mathrm{Y})$.

b. Berdasarkan nilai $\mathrm{r}_{\text {hitung }}$ (pearson correalation), diketahui nilai $\mathrm{r}_{\text {hitung }}$ untuk hubungan variabel self- esteem $\left(\mathrm{X}_{1}\right)$ dengan variabel efektivitas kerja (Y) adalah sebesar 0,477 > 0,188 (df. 109-2), maka dapat disimpulkan ada hubungan antara variabel self-esteem $\left(\mathrm{X}_{1}\right)$ dengan variabel efektivitas kerja $(\mathrm{Y})$. Berikutnya diketahui nilai $\mathrm{r}_{\text {hitung }}$ untuk hubungan variabel komunikasi interpersonal $\left(\mathrm{X}_{2}\right)$ dengan variabel efektivitas kerja $(\mathrm{Y})$ adalah sebesar 0,505 $>0,188$ (df. 109-2), maka dapat disimpulkan ada hubungan antara variabel komunikasi interpersonal $\left(\mathrm{X}_{2}\right)$ dengan variabel efektivitas kerja $(\mathrm{Y})$. Dari hasil hitung pearson correlation tersebut karena $\mathrm{r}_{\text {hitung }}$ dalam analisis ini bernilai positif, dengan demikian dapat diartikan adanya hubungan antara kedua variabel tersebut bersifat positif atau dengan kata lain semakin meningkatnya self- esteem dan komunikasi interpersonal maka akan meningkat pula efektivitas kerja guru.

c. Pada tabel nampak tanda bintang $(*=$ signifikan), dari output di atas diketahui bahwa nilai korelasi antara masing-masing variabel yang dihubungkan mempunyai dua tanda bintang (**= sangat signifikan), ini dapat diartikan bahwa terdapat korelasi antara variabel yang dihubungkan dengan taraf signifikan $1 \%$.

\section{Model Sub-struktural}

Besarnya pengaruh self esteem dan komunikasi interpersonal terhadap efektivitas kerja secara parsial dapat dipaparkan pada Tabel 2. Berdasarkan persamaan struktural sub-struktur 1, dapat diartikan bahwa efektivitas kerja guru (Y) dipengaruhi oleh self esteem (X1) dan komunikasi interpersonal (X2) secara simultan dan signifikan sebesar 33,40\% dan sisanya sebesar $66,60 \%$ dipengaruhi oleh variabel-variabel lain di luar penelitian ini. Semakin baik self-esteem (X1) yang diterima dan dikerjakan oleh karyawan, maka efektivitas kerja guru (Y) juga akan semakin tinggi. Begitu juga sebaliknya, semakin buruk self esteem (X1) yang diterima dan dikerjakan oleh karyawan, maka efektivitas kerja guru (Y) juga akan semakin rendah. Demikian pula semakin baik komunikasi interpersonal (X2) yang diterima dan dikerjakan oleh karyawan, maka efektivitas kerja guru (Y) juga akan semakin tinggi. Demikian sebaliknya, semakin buruk komunikasi interpersonal (X2) yang diterima dan dikerjakan oleh karyawan, maka efektivitas kerja guru (Y) juga akan semakin rendah 
Tabel 2. Pengaruh self esteem dan komunikasi interpersonal terhadap efektivitas kerja guru secara parsial

\begin{tabular}{|c|c|c|c|c|c|c|}
\hline \multirow{2}{*}{ Mode } & & \multicolumn{2}{|c|}{ Unstandardized Coefficients } & \multirow{2}{*}{$\begin{array}{c}\text { Standardized Coefficients } \\
\text { Beta }\end{array}$} & \multirow[b]{2}{*}{$\mathrm{t}$} & \multirow[b]{2}{*}{ Sig. } \\
\hline & & B & Std. Error & & & \\
\hline \multirow[t]{3}{*}{1} & (Constant) & 35,213 & 13,485 & & 2,611 &, 010 \\
\hline & $\mathrm{X} 1$ &, 350 & ,099 & ,314 & 3,541 & ,001 \\
\hline & $\mathrm{X} 2$ & 398 & 097 & 365 & 4,117 & 000 \\
\hline
\end{tabular}

a. Dependent Variable: Y

\section{Pengaruh langsung}

a. Pengaruh Langsung $\mathrm{X}_{1}$ Terhadap $\mathrm{Y}$

Berikut ini akan ditampilkan pengaruh langsung maupun tidak langsung self-esteem $\left(\mathrm{X}_{1}\right)$ dan komunikasi interpersonal $\left(\mathrm{X}_{2}\right)$ terhadap efektivitas kerja guru $(\mathrm{Y})$ yang tercantum tabel berikut ini. Dapat dilihat bahwa pengaruh langsung self esteem $\left(\mathrm{X}_{1}\right)$ terhadap efektivitas kerja guru $(\mathrm{Y})$ tanpa memperhatikan komunikasi interpersonal $\left(\mathrm{X}_{2}\right)$ adalah sebesar $22,70 \%$. Sehingga pengaruh self-esteem $\left(\mathrm{X}_{1}\right)$ baik secara langsung terhadap efektivitas kerja guru $(\mathrm{Y})$ adalah $22,70 \%$.

Dengan demikian peningkatan yang terjadi pada efektivitas kerja guru-guru SMP swasta yang berada di wilayah Kecamatan Gunung Putri Kabupaten Bogor sebesar 22,70\% dipengaruhi oleh peningkatan self-esteem guru-guru SMP swasta yang berada di wilayah Kecamatan Gunung Putri Kabupaten Bogor.

b. Pengaruh langsung X2 terhadap Y

Dapat dilihat bahwa pengaruh langsung komunikasi interpersonal $\left(\mathrm{X}_{2}\right)$ terhadap efektivitas kerja guru (Y) tanpa memperhatikan self esteem $\left(\mathrm{X}_{1}\right)$ adalah sebesar $25,50 \%$. Sehingga pengaruh komunikasi interpersonal $\left(\mathrm{X}_{2}\right)$ baik secara langsung terhadap efektivitas kerja guru (Y) adalah 25,50\%. Dengan demikian peningkatan yang terjadi pada efektivitas kerja guru-guru SMP swasta yang berada di wilayah Kecamatan Gunung Putri Kabupaten Bogor sebesar 25,50\% dipengaruhi oleh peningkatan komunikasi interpersonal guru-guru SMP swasta yang berada di wilayah Kecamatan Gunung Putri Kabupaten Bogor.

Berdasarkan perhitungan tersebut di atas, maka dapat dikemukakan bahwa self esteem $\left(\mathrm{X}_{1}\right)$ dan komunikasi interpersonal $\left(\mathrm{X}_{2}\right)$ secara bersama mempunyai pengaruh secara langsung terhadap efektivitas kerja guru $(\mathrm{Y})$ sebesar $42,70 \%$. Sedangkan besarnya pengaruh variabel lain yang tidak dimasukkan dalam penelitian terhadap efektivitas kerja guru (Y), yaitu sebesar $11,80 \%$ (100-88,20). Berdasarkan hasil perhitungan juga dapat diketahui bahwa variabel yang memiliki pengaruh terbesar terhadap efektivitas kerja guru $(\mathrm{Y})$ adalah komunikasi interpersonal $\left(\mathrm{X}_{2}\right)$, yaitu sebesar 45,50\%. Sedangkan pengaruh terkecil terhadap kinerja pegawai pemerintah daerah (Y) adalah self esteem (X1), yaitu sebesar 42,70\%

\section{1) Pengaruh Self-Esteem terhadap Efektivitas Kerja Guru.}

Hasil penelitian menunjukkan terdapat hubungan positif antara self-esteem dengan efektivitas kerja guru, artinya selfesteem dipersepsikan sangat mempengaruhi peningkatan efektivitas kerja guru. Kekuatan hubungan antara self-esteem dengan efektivitas kerja guru pada nilai koefisien korelasi sebesar 0,477. Pengaruh efektivitas kerja guru yang terkait erat dengan selfesteem terlihat dari nilai koefisien determinasi $\left(\mathrm{r}_{\mathrm{y}}{ }^{2}\right)$ sebesar 0,227 , artinya pengaruh langsung efektivitas kerja guru sebesar $22,70 \%$ dapat dijelaskan oleh self-esteem sedangkan $77,30 \%$ sisanya dipengaruhi oleh faktor-faktor lain.

Hasil positif yang sangat signifikan antara self-esteem dengan efektivitas kerja guru, yang merupakan hubungan fungsional, artinya peningkatan self-esteem guru meningkat karena efektivitas kerjanya. Hal ini selaras dengan pendapat Murk (2006) yang menyatakan bahwa seseorang akan menyukai dan menghargai dirinya apabila ia menerima diri pribadinya. Penilaian seseorang terhadap dirinya akan mempengaruhi proses berpikir, perasaan, keinginan atau keputusan-keputusan yang diambil dan tujuan hidupnya, yang kemudian menentukan arah menuju keberhasilan dan kegagalan dalam menyelesaikan suatu tugas dan masalah. Pandangan positif terhadap diri akan mendukung keputusan yang mengarah pada keberhasilan. Implikasinya adalah jika komponen-komponen yang berhubungan dengan self-esteem dimiliki guru, maka akan meningkatkan efektivitas kerjanya. Temuan penelitian ini sejalan pula dengan penelitian Rezvan Shirmohammadi (2016) yang menyimpulkan bahwa harga diri siswa yang lebih tinggi, ditambah gaya mengajar guru yang berpusat pada siswa, memiliki hubungan positif yang signifikan $(\rho<0,01)$ dengan efektivitas mengajar. Penelitian ini menyimpulkan bahwa kreativitas guru dapat ditingkatkan melalui self-esteem. Mengacu pada paparan di atas, maka self-esteem merupakan salah satu faktor penentu dalam meningkatkan efektivitas kerja guru.

\section{2) Komunikasi Interpersonal terhadap Efektivitas Kerja Guru}

Hasil penelitian yang menunjukkan terdapat hubungan positif antara komunikasi interpersonal dengan efektivitas kerja guru dimaknai bahwa guru yang memiliki komunikasi interpersonal tinggi berdampak pada efektivitas kerja guru yang tinggi. Kekuatan hubungan antara komunikasi interpersonal dengan efektivitas kerja guru terlihat pada nilai koefisien korelasi sebesar $\mathrm{r}=0,505$. Keragaman pada efektivitas kerja guru yang terkait dengan komunikasi interpersonal tercermin pada nilai koefisien determinasi 0,255 , dapat diartikan pengaruh langsung komunikasi interpersonal terhadap efektivitas kerja sebesar $25,50 \%$, sedangkan $74,50 \%$ sisanya dipengaruhi oleh faktor-faktor lain. Hasil penelitian menunjukkan terdapat hubungan positif yang 
sangat signifikan antara komunikasi interpersonal dengan efektivitas kerja guru, dan hubungan tersebut merupakan hubungan fungsional yang memiliki arti bahwa komunikasi interpersonal yang baik meningkatkan efektivitas kerja guru. Hal ini didukung oleh pendapat Luthans (2011) yang menyatakan bahwa penekanan utama komunikasi interpersonal adalah transfer informasi dari satu orang ke orang lain. Komunikasi dipandang sebagai metode dasar perubahan perilaku, dan itu menggabungkan proses psikologis (persepsi, pembelajaran, dan motivasi) di satu sisi, dan bahasa di sisi lain. Komunikasi interpersonal yang efektif akan membantu guru untuk lebih mudah dalam bergaul, beradaptasi dan menyampaikan pendapat kepada teman atau kepada atasan. Dengan demikian komunikasi interpersonal yang tinggi akan meningkatkan efektivitas kerja guru.

Temuan penelitian ini mendukung hasil studi Nasiri Mehran (2012) berjudul Relationship between Interpersonal Communication Skills and Effectiveness. Dengan koefisien Korelasi $r=0,814$ ( $P \leq 0.05)$, hasil penelitian ini membuktikan ada hubungan yang signifikan antara ketiga variabel penelitian, yaitu keterampilan komunikasi interpersonal dan efektivitas kerja, dan terdapat hubungan positif yang signifikan antara komponen keterampilan komunikasi (verbal, mendengarkan, dan umpan balik) dan efektivitas kerja.

\section{SIMPULAN}

Mengacu pada analisis terhadap data hasil penelitian, peneliti dapat menyimpulkan hasilnya sebagai berikut: Terdapat pengaruh positif self-esteem (X1) terhadap efektivitas kerja guru (Y) tanpa memperhatikan komunikasi interpersonal (X2) adalah sebesar $22,70 \%$.Terdapat pengaruh positif komunikasi interpersonal (X2) terhadap efektivitas kerja guru ( $\mathrm{Y}$ ) tanpa memperhatikan self-esteem $\left(\mathrm{X}_{1}\right)$ adalah sebesar $25,50 \%$.

\section{REFERENSI}

Adler, Ronald B. (2006). Interplay: The Process of Interpersonal Communication. New York: Oxford University Press. Cascio, W.F. (2004). Applied Psychology in human resource Manajement. $6^{\text {th }}$ Edition. New Jersey : New Prentice-Hall inc Danim, S., (2004). Motivasi Kepemimpinan dan Efektivitas Kelompok. Jakarta: Rineka Cipta

DeVito, Joseph H. (2002). The Interpersonal Communication Book. Person Education.Inc

Gibson, James L. John Ivanicevich, James H. Donnelly, Jr and Robert Konopaske. (2009). Organization. Behavior, Structure, Process 14th Edition. New York: McGraw-Hill

Gibson, J.L, Ivancevich, J.M, \& Donelly, J.H, Konopaske, R. (2012). Organizations, Behavior, Processes. Edisi 14. Chicago: Irwin.

Luthans, F. (2011). Organizational Behavior. $12^{\text {th }}$ Edition. New York : McGraw-Hill Education.

Luxmoore, N. (2008). Feeling like Crap: Young People and the Meaning of Self-Esteem.London: Jessica Kingsley Publishers.

Mehran, Nasiri \& Shafiee, Shahram \& Hossein, Sepasi. (2018). Relationship between Communication Skills and Effectiveness. 101-106. European Journal of Social Sciences 13(3):387-398

Murk, J Christopher. (2006). Self esteem, research, Theory, and practice. New york: Springer publishing company.

Nelson, D.L \& Quick, J.C. (2006). Organizatonal Behavior Foundations Realities and Challenges. Thompson South Western. United States of America

Rahman, A, Agus. (2013). Psikologi Sosial: Integrasi Pengetahuan Wahyu dan Pengetahuan Empirik. Jakarta: Rajawali Pers. Pearson, J. C. (2010). Human Communication. New York : Aptara

Rezvan Shirmohammadi, (2016). Determining the relationship between self-esteem with quality of teaching high school students in Isfahan. International Journal Of Humanities And Cultural Studies

Robbins, Stephen P. dan Timothy A. Judge. (2007). Organizational Behavior, $12^{\text {th }}$ Ed. New Jersey: Pearson Prentice Hall. Riggio, R. (2012). Introduction to Industrial and Organizational Psychology. $6^{\text {th }}$ Edition. New Jersey US : New Jersey Inc. Schiraldi, G. R. (2007). 10 Solution For Building Self-esteem. United States : New Harbinger Publications, Inc.

Suchyadi, Y., Karmila, N., \& Safitri, N. (2019). Kepuasan Kerja Guru Ditinjau Dari Peran Supervisi Kepala Sekolah Dasar Negeri Di Kecamatan Bogor Utara. JPPGuseda | Jurnal Pendidikan \& Pengajaran Guru Sekolah Dasar, 2(2), 91-94. https://doi.org/10.33751/jppguseda.v2i2.1453

Sorensen, M. J. (2006). Breaking The Chain Of Low Self-Esteem. Second Edition. Sherwood : Wolf Publishing Co.

Supardi. (2013). Sekolah Efektif, Konsep Dasar dan Praktiknya. Jakarta: Raja Grafindo Persada 